\title{
Role of Hyperbilirubinemia as a Diagnostic Tool to Predict Gangrenous/Perforated Appendicitis: An Observational Study
}

\author{
Mohak Mankad ${ }^{\odot 1}$, Pranjal Sangole ${ }^{\circledR 2}$, Gyaneshwar Rao ${ }^{\circledR 3}$ \\ ${ }^{1}$ Post Graduate Student, Department of Surgery, Gujarat Adani Institute of Medical Science, Bhuj, Gujarat, India, ${ }^{2}$ Assistant Professor, Department of Surgery, Gujarat \\ Adani Institute of Medical Science, Bhuj, Gujarat, India, ${ }^{3}$ Professor and Head, Department of Surgery, Gujarat Adani Institute of Medical Science, Bhuj, Gujarat, India.
}

\section{Abstract}

Background: Elevation in serum bilirubin was reported recently, but the importance of the raised total bilirubin has not been stressed in acute appendicitis and appendicular perforation. The aim of the study was to establish the role of hyperbilirubinemia as a new diagnostic tool to predict gangrenous/perforated appendicitis. Subjects and Methods: This was a prospective observational study, which was conducted at the Gujarat Adani Institute of Medical Science, Bhuj, Kutch, Gujarat, India. A total of 100 patients clinically diagnosed as appendicitis from August 2018 to August 2019 at Gujarat Adani Institute of Medical Science, Bhuj, Kutch, Gujarat, India. Patients were clinically evaluated by detailed history, routine examination on initial contact with patients and the routine investigations as per surgery and anesthesia requirements with inclusion of serum total bilirubin. Based on histopathological examination patients will be categorized as positive (acute appendicitis with perforation and/or gangrene) and negative (acute appendicitis without perforation or gangrene). Results: Out of 100 patients, 20 were managed conservatively (mass formation) and was called for interval appendectomy after 6 weeks. In acute catarrhal appendicitis group 47 patients showed normal total bilirubin levels, whereas 8 patients showed increase in levels of total bilirubin. In gangrenous appendicitis group all 10 patients showed elevated serum total bilirubin levels In perforated appendicitis group consisted of 15, 11 patients showed elevated serum bilirubin levels and 4 patients showed normal total bilirubin levels. Conclusion: Serum bilirubin is easily available test and cheap and can be estimated from the sample of blood drawn for routine blood investigations.

Keywords: Acute Appendicitis, Kutch, Perforation, Serum bilirubin

Corresponding Author: Pranjal Sangole, Assistant Professor, Department of Surgery, Gujarat Adani Institute of Medical Science, Bhuj, Gujarat, India.

E-mail: drpranjalsangole@gmail.com

Received: 29 December 2019

Revised: 08 February 2020

Accepted: 20 February 2020

Published: 26 May 2020

\section{Introduction}

Acute appendicitis is the most common cause of "acute surgical abdomen". ${ }^{[1,2]}$ Appendicectomy is the emergency abdominal operation most frequently performed and is often the first major procedure performed by a surgeon in training. Despite advances in the radiological and laboratory investigations, the diagnosis of appendicitis remains a dilemma. Based on a combination of history, physical examination and laboratory studies experienced clinicians accurately diagnose appendicitis about $80 \%$ of the time. ${ }^{[3]}$ Delay in diagnosis and surgery for this condition may lead to various complications like perforation, abdominal abscess, urinary retention, small bowel obstruction and peritonitis causing an increase in morbidity and even mortality of the patients. Acute appendicitis is the most common intra-abdominal infectious focus in a surgical patient and Escherichia coli and Bacteroides fragilis are the most frequent bacterial isolates in this condition. ${ }^{[4]}$ In appendicitis, compromised appendix wall integrity leads to translocation of bacteria and endotoxins from the appendix lumen into the portal system. ${ }^{[5]}$

The percentage of appendicectomies performed, where normal appendix found, varies from $15-50 \%$ and postoperative complications can occur in up to $50 \%$ of these patients. ${ }^{[4,5]}$ Delay in diagnosis of acute appendicitis leads to perforation and peritonitis with increased mortality. Appendicular perforation ranges $50-90 \%$ in various series. ${ }^{[6,7]}$ The importance of laboratory investigations like White Blood Cell (WBC) counts and $\mathrm{C}$-reactive protein (CRP) etc. values has been stressed to supplement the clinical diagnosis and to reduce the frequency of unnecessary appendicectomy. ${ }^{[8]}$ The importance of Ultrasonography (USG) as a diagnostic tool for appendicitis has been widely known and studied. ${ }^{[8,9]}$ Various scores combining clinical features and laboratory investigations, have also 
been developed to reach the diagnosis, such as the Alvarado score and the Modified Alvarado score. ${ }^{[10,11]}$ However, till now there is no confirmatory laboratory marker for the preoperative diagnosis of acute appendicitis and appendicular perforation. Elevation in serum bilirubin was reported recently, but the importance of the raised total bilirubin has not been stressed in acute appendicitis and appendicular perforation. ${ }^{[12]}$ It is well established that when microorganisms invade the body, leukocytes defend it and leads to increase in the leukocyte count. Microbial invasion in the appendix leads to transmigration of microbe and the release of proinflammatory cytokines such as TNF-alpha, IL6 and cytokines. They reach the liver through Superior mesenteric vein (SMV), either directly or indirectly by altering the hepatic blood flow, produce inflammation, abscess or dysfunction of liver. ${ }^{[13,14]}$

Total bilirubin levels upon admission can be used in conjunction with other diagnostic tests such as ultrasonography and routine investigations to help determine the presence of complicated appendicitis and aid in proper clinical management.

To avoid unnecessary delay in surgery, Need for higher antibiotic coverage, Patient counseling. The aim of the study was to establish the role of hyperbilirubinemia as a new diagnostic tool to predict gangrenous/perforated appendicitis.

\section{Subjects and Methods}

This was a prospective observational study, which was conducted at the Gujarat Adani Institute of Medical Science, Bhuj, Kutch, Gujarat, India. Patients were briefed about the study and their consent was taken. A total of 100 patients clinically diagnosed as appendicitis from August 2018 to August 2019 at Gujarat Adani Institute of Medical Science, Bhuj, Kutch, Gujarat, India. Patients were clinically evaluated by detailed history, routine examination on initial contact with patients and the routine investigations as per surgery and anesthesia requirements with inclusion of serum total bilirubin.

The aim of the study was to find out the role of serum Bilirubin as a laboratory marker to aid in the diagnosis of acute appendicitis and to evaluate whether elevated bilirubin levels have a predictive potential for the diagnosis of the severity of Appendicitis.

Serum total bilirubin results will be compared with laboratory reference values given in Table 1. These cases will be operated and clinical diagnosis will be confirmed per-operatively and post-operatively by histopathological examination. Final histopathological examination will be considered as a gold standard for diagnosing and categorizing patients as having normal appendix, acute appendicitis and acute appendicitis with perforation and/or gangrene.

Based on histopathological examination patients will be categorized as positive (acute appendicitis with perforation and/or gangrene) and negative (acute appendicitis without perforation or gangrene).

\section{Results}

Total of 100 patients were admitted with diagnosis of acute appendicitis. Out of 100 patients, 20 were managed conservatively (mass formation) and was called for interval appendectomy after 6 weeks. Out of 100 patients of appendicitis there was an increase in incidence of acute appendicitis in age group of 15 to 35 with 60 patients. There is increased incidence in male population with male female ration of $1.5: 1$. The mean total bilirubin was found to be $0.8 \mathrm{mg} / \mathrm{dl}$ in acute catarrhal appendicitis and $1.44 \mathrm{mg} / \mathrm{dl}$ in acute complicated appendicitis respectively.

As shown in Table 2 out of 80 patients, 55 patients had acute catarrhal appendicitis, 10 patients had gangrenous appendicitis, 15 patients had perforated appendicitis, and we never encountered normal appendix either in intra op or post op.

In acute catarrhal appendicitis group 47 patients showed normal total bilirubin levels, whereas 8 patients showed increase in levels of total bilirubin. In gangrenous appendicitis group all 10 patients showed elevated serum total bilirubin levels In perforated appendicitis group consisted of 15, 11 patients showed elevated serum bilirubin levels and 4 patients showed normal total bilirubin levels. Sensitivity of serum bilirubin in case of perforated/ gangrenous appendicitis was found to be $90.02 \%$. Specificity of serum bilirubin was found in case of perforated or gangrenous appendicitis was found to be $90.35 \%$. Positive predictive value and negative predicting value of serum bilirubin in perforated/gangrenous appendicitis was found to be $82.1 \%$ and $94.9 \%$ respectively with $p$ value of 0.01 .

\begin{tabular}{|lll|}
\hline \multicolumn{3}{|c|}{ Table 1: Reference values of serum bilirubin } \\
\hline Test & Normal range & Test \\
Total & $1.2 \mathrm{mg} / \mathrm{dl}$ & Total \\
\hline Direct & $0.2 \mathrm{mg} / \mathrm{dl}$ & Direct \\
\hline
\end{tabular}

\section{Discussion}

In acute appendicitis or appendicular perforation, inflammatory response causes appendix to become more edematous and ischemic. This causes transmigration or translocation of bacteria, toxins, and cytokines leading to endotoxemia/bacteraemia. Invasion of bacteria into the hepatic parenchyma interferes with the physiology of excretion of bile and leads to hyperbilirubinemia. 


\begin{tabular}{|llll|}
\hline \multicolumn{2}{|c|}{ Table 2: Showing HPE correlation } & \\
\hline \multicolumn{1}{|c|}{ Histopatholo } & $\begin{array}{l}\text { Total } \\
\text { bilirubin } \\
<\mathbf{1 . 2} \mathbf{~ m g / d l}\end{array}$ & $\begin{array}{l}\text { Total } \\
\text { bilirubin } \\
>\mathbf{1 . 2} \mathbf{~ m g / d l}\end{array}$ & Total \\
\hline $\begin{array}{l}\text { Acute } \\
\text { appendicits }\end{array}$ & 47 & 8 & 55 \\
$\begin{array}{l}\text { Gangrenous } \\
\text { appendicitis }\end{array}$ & 0 & 10 & 10 \\
$\begin{array}{l}\text { Perforated } \\
\text { appendicitis }\end{array}$ & 11 & 4 & 15 \\
$\begin{array}{l}\text { Normal } \\
\text { appendix }\end{array}$ & 0 & 0 & 0 \\
\hline \begin{tabular}{l} 
Total \\
\hline
\end{tabular} & 58 & 22 & 80 \\
\hline
\end{tabular}

In appendicitis, compromised appendix wall integrity leads to translocation of bacteria and endotoxins from the appendix lumen into the portal system. ${ }^{[5]}$ Bacteremia is known to cause endotoxemia leading to impaired excretion of bilirubin from the bile canaliculi. ${ }^{[3]}$ This study has shown there is a high sensitivity and specificity serum bilirubin $90.02 \%$ and $90.35 \%$ respectively with good positive predictive value of $82.1 \%$ and high negative predictive value of $94.9 \%$ with $\mathrm{p}$ value of 0.001 in case of complicated appendicitis, and should alert the surgeon regarding the possibility of this diagnosis.

Cheekuri et al in 2017 conducted a prospective study Hyperbilirubinemia as a predictor of the severity of acute appendicitis- an observational study with sample size of 110 showed results of sensitivity 94\%, specificity 66\%, PPV $88.5 \%$, NPV $80 \%$. $^{[15]}$

D'souza et al conducted a prospective study Bilirubin; a diagnostic marker for appendicitis with sample size of 143 showed results of sensitivity $70 \%$, specificity $82 \%$, PPV $47 \%$, NPV 93\%. ${ }^{[4]} \mathrm{S}$. Khan in 2008 conducted a prospective study of total bilirubin levels in appendicitis with sample size of 110 showed a results of sensitivity $87 \%$, specificity $100 \%$, PPV 100\%, NPV 17.3\% Khan S et al in his study concluded that elevated total serum bilirubin, without severe abnormalities in the value of liver enzymes is a good indicator of acute appendicitis. ${ }^{[12]}$ Estrada $\mathrm{J}$ et al in his study found significant relationship between the presence or absence of appendicular gangrene and perforation with the presence of hyperbilirubinemia. ${ }^{[16]}$ Pre-operative serum total bilirubin can diagnose acute complicated appendicitis from catarrhal appendicitis with fair degree of accuracy.

\section{Conclusion}

Serum bilirubin is easily available test and cheap and can be estimated from the sample of blood drawn for routine blood investigations. If serum bilirubin is added to existing lab investigations, then diagnosis of complicated appendicitis can be made with fair degree of accuracy which in turn helps in reducing the need for CECT, unnecessary delay in surgery can be avoided.

\section{References}

1. Humes DJ, Simpson J. Acute appendicitis. $\mathrm{Br}$ Med J. 2006;333(7567):530-534. Available from: https://dx.doi.org/10.1136/bmj.38940.664363.ae. doi:10.1136/bmj.38940.664363.ae.

2. Neidhardt JP, Caillot JL, Voiglio EJ. Acute appendicitis and its complications. Diagnosis, treatment. Rev Prat. 1998;48(5):559-563.

3. Drake FT, Flum DR. Improvement in the Diagnosis of Appendicitis. Adv Surg. 2013;47:299-328.

4. D'souza N. A diagnostic marker for appendicitis. Int J Surg. 2013;11(10):1114-1121.

5. Giordano S, Pääkkönen M, Salminen P, Grönroos JM. Elevated serum bilirubin in assessing the likelihood of perforation in acute appendicitis: A diagnostic meta-analysis. Int J Surg. 2013;11(9):795-800. Available from: https://dx.doi.org/10. 1016/j.ijsu.2013.05.029. doi:10.1016/j.ijsu.2013.05.029.

6. Titte SNV, McCabe CJ, Ottinger LW. Delayed appendectomy for appendicitis: Causes and consequences. Am J Emerg Med. 1996;14(7):620-622. Available from: https://dx. doi.org/10.1016/s0735-6757(96)90074-1. doi:10.1016/s07356757(96)90074-1.

7. Temple CL, Huchcroft SA, Temple WJS. Natural History of appendicitis in adult: A prospective study. Ann Surg. 1995;221:78-78.

8. Puylaert JBCM, Rutgers PH, Lalisang RI, de Vries BC, van der Werf SDJ, Dörr JPJ, et al. A Prospective Study of Ultrasonography in the Diagnosis of Appendicitis. New England J Med. 1987;317(11):666-669. Available from: https://dx.doi.org/10.1056/nejm198709103171103. doi:10.1056/nejm198709103171103.

9. Lim HK, Lee WJ, Lee SJ, Namgung S, Lim JH. Focal appendicitis confined to the tip: diagnosis at US. Radiology. 1996;200(3):799-801. Available from: https://dx.doi.org/10.1148/radiology.200.3.8756934. doi:10.1148/radiology.200.3.8756934.

10. Alvarado A. A practical score for the early diagnosis of acute appendicitis. Ann Emerg Med. 1986;15(5):557-564. Available from: https://dx.doi.org/10.1016/s0196-0644(86)80993-3. doi:10.1016/s0196-0644(86)80993-3.

11. Kalan M, Tabbot O, Cunlife WJ, Rich AJ. Evaluation of the modified Alvrado score in the diagnosis of acute appendicitis. A prospective study. Ann R Cool Surg Engl. 1994;76:418-427.

12. Khan S. Evaluation of hyperbilirubinemia in acute inflammation of appendix: a prospective study of 45 cases. Kathmandu Univ Med J. 2006;4(3):281-290.

13. Juric I, Primorac D, Zagar Z. Biocic Frequency of portal and systemic bacteremia in acute appendicitis. Pediatr Int. 2001;43(2):152-158.

14. Wang P, Chaudry IH. Mechanism of hepatocellular dysfunction during hyperdynamic sepsis. Am J Physiol. 1996;270(5):R927R938. Available from: https://dx.doi.org/10.1152/ajpregu. 
1996.270.5.r927. doi:10.1152/ajpregu.1996.270.5.r927.

15. Cheekuri SK, Mohanty A, Ganesh T, Kannan R, Smile R. Hyperbilirubinemia as a predictor of the severity of acute appendicitis - an observational study. Int Surg J. 2017;4(4):1341-1341. Available from: https://dx.doi.org/10.18203/2349-2902.isj20171138. doi:10.18203/2349-2902.isj20171138.

16. Estrada JJ, Petrosyan M, Barnhart J, Tao M, Sohn H, Towfigh $\mathrm{S}$, et al. Hyperbilirubinemia in Appendicitis: A New Predictor of Perforation. J Gastrointest Surg. 2007;11(6):714-718. Available from: https://dx.doi.org/10.1007/s11605-007-01565. doi:10.1007/s11605-007-0156-5.

Copyright: (C) the author(s), 2020. It is an open-access article distributed under the terms of the Creative Commons Attribution License (CC BY 4.0), which permits authors to retain ownership of the copyright for their content, and allow anyone to download, reuse, reprint, modify, distribute and/or copy the content as long as the original authors and source are cited.

How to cite this article: Mankad M, Sangole P, Rao G. Role of Hyperbilirubinemia as a Diagnostic Tool to Predict Gangrenous/Perforated Appendicitis: An Observational Study. Acad. J Surg. 2020;3(1):52-55.

DOI: dx.doi.org/10.47008/ajs/2020.3.1.11

Source of Support: Nil, Conflict of Interest: None declared. 